Int. J. Electrochem. Sci., 15 (2020) $7027-7038$

International Journal of

ELECTROCHEMICAL

SCIENCE

www.electrochemsci.org

\title{
Optimization of Cathodic Protection System for River-Crossing District Heating Pipeline using Computational Analysis: Part II. The effective location of anodes
}

\author{
Min-Sung Hong, Jung-Gu Kim* \\ School of Advanced Materials Engineering, Sungkyunkwan University, 300 Chunchun-Dong, Jangan- \\ Gu, Suwon 440-746, South Korea; \\ *E-mail: kimjg@ @sku.edu
}

doi: $10.20964 / 2020.07 .83$

Received: 18 February 2020 / Accepted: 18 May 2020 / Published: 10 June 2020

In the previous study, we designed cathodic protection (CP) for river-crossing District Heating (DH) pipeline with appropriate environmental factors. The study verified the satisfaction of the CP criteria at the target structure with fixed anode location. However, consideration of the optimized anode location is a very important factor; therefore, in this case study, we used computational analysis to optimize the location of anode for effective $\mathrm{CP}$. The CP potential variation was observed according to the position of the west anode. In the case of $74 \mathrm{~A}$, which is the current calculated by theoretical method, the maximum $\mathrm{CP}$ potential decreases by increasing the anode distance up to $400 \mathrm{~m}$; however, it did not satisfy the CP criteria in all anode locations. The 100 A current, which is the optimized CP current without anode movement from the previous study, showed a similar tendency. All of the results satisfied the CP criteria, and the lowest potential was observed at $500 \mathrm{~m}$. In all of the studied cases, it can be concluded that the optimized distance of anode is between 400 and 500 in the range 74 and 100 A. Consequently, the optimized CP design can be achieved at the anode location of $400 \mathrm{~m}$ with CP current of $83 \mathrm{~A}$. This study shows the significance of anode location and distribution to structure in $\mathrm{CP}$ design. Obviously, computational analysis should be conducted to obtain more stable and reliable $\mathrm{CP}$ design in the real field.

Keywords: Polarization test; Computational Analysis; River-Crossing Pipeline; Cathodic Protection; Anode; Impressed Current Cathodic Protection;

\section{$\underline{\text { FULL TEXT }}$}

(C) 2020 The Authors. Published by ESG (www.electrochemsci.org). This article is an open access article distributed under the terms and conditions of the Creative Commons Attribution license (http://creativecommons.org/licenses/by/4.0/). 